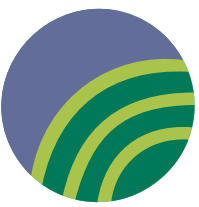

\title{
Babak Anasori
}

\section{Research assistant professor and microscopic photographer}

By Rahul Rao

$\mathrm{T}$ he images found on textbook or journal covers can do a wonderful job of belying the frequently dry content within. The visuals are often colorful, bright, and fascinating, captivating the interest of the nonscientific reader by turning subjects that could be dull into subjects that can be attention-grabbing and exciting.

To that end, a common fixture at the Materials Research Society (MRS) Meetings is the "Science as Art" competition, intended to show that scientific research can have a more whimsical, artistic side. A mainstay at these competitions is Babak Anasori, whose images have won awards at competitions hosted by MRS, the National Science Foundation, and ASM International. Babak's images have also graced numerous book and journal covers, and have been featured on American Physical Society and Carl Zeiss calendars.

Originally from Iran, Babak has been at Drexel University since 2009, first as a doctoral student, and currently as a research assistant professor. Babak's current research efforts involve finding new applications for two-dimensional (2D) materials, in particular, 2D carbides and nitrides, a category of materials known as MXenes.

Babak initially had little exposure to materials science and, at first, intended to enter either civil or mechanical engineering. However, in Babak's own words, "materials science selected me." As soon he began studying materials science in college, he was fascinated, and he decided to continue exploring.

Babak believes one of his other interests - his imagescan help bring more exposure and publicity to the world of materials science. At least, that is his stated objective: "I try to use these microscopy images, or anything that can simplify the message, to bring more visibility to materials science." Babak's images are visualizations he captures, using an electron microscope, of real and actively researched materials.

"The first time I saw one of these artistic microscopy images," he said, "I was fascinated by them, and I wished I could create one." When Babak realized that other scientists were involved in "Science as Art" competitions, his interest was piqued, and he set out to create images of his own.

One of Babak's wishes is that these competitions have more visibility. Most of them are limited to certain associations or societies, often taking place at their respective conferences, and are not open to the public. It is because of this, Babak believes, that few members of the general public are aware that science can have artistic value, which-he thinks - would be a particular draw for younger audiences interested in science.

Babak does not consider himself an actual photographer.
"I have a mindset of research," he said. "I don't have the mindset of a photographer to go and find nice features to take images." Because of this, Babak's favorite artistic subjects are typically his own work, a subject that he wishes to help broadcast to a wider audience.

Babak believes that scientific research is too difficult to follow for most audiences, even with the Internet allowing easier access than ever. "If you put [research] online, even on the most visited website, no one can understand it, so the general public will just ignore it," he said. "But when you put a nice, eye-catching image, then you will draw attention, and people will at least spend a few minutes to read about it."

Therefore, he uses his images as an educational and outreach tool: "By just looking at [the images] and trying to understand what I've done with the research, sometimes I can relate the story of my research to the picture." Relating this story helps Babak engage audiences with the subject of his research - even when the story itself is entirely fictional, as in the example of the composite dragon, seen below. With his use of scientific instruments to create something beautiful, Babak added, "I can call myself a microscopic photographer."

Rahul Rao is a student at Vanderbilt University studying Physics and English.

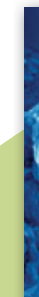

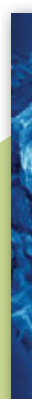

This image shows a fractured surface of a magnesium matrix composite reinforced with titanium aluminum carbide, $\mathrm{Ti}_{2} \mathrm{AIC}$, MAX phase. The dragon is a kinked $\mathrm{Ti}_{2} \mathrm{AIC}$, and the surrounding material, including the fire, is the Mg matrix. Credit: Babak Anasori and Michel W. Barsoum. a layered ternary carbide

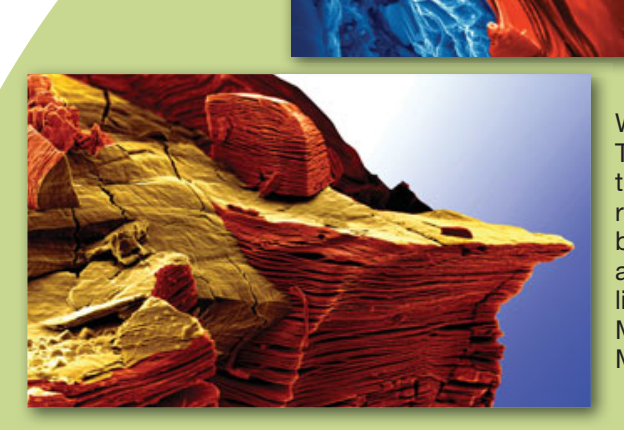

When the layered ternary compound, $\mathrm{Ti}_{3} \mathrm{AlC}_{2}$, is placed in hydrofluoric acid, the Al layers are selectively etched away, resulting in $2 \mathrm{D}$ layers of $\mathrm{Ti}_{3} \mathrm{C}_{2}$ weakly bonded to each other. The image shows a number of these particles, where exfoliation is obvious. Credit: Babak Anasori, Michael Naguib, Yury Gogotsi, and Michel W. Barsoum. 